\title{
Perception of Iraqi youth towards social and psychological impact of COVID-19
}

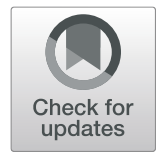

Ameel F. Al Shawi ${ }^{1 *}$ (D) and Riyadh Lafta ${ }^{2}$

\begin{abstract}
Background: COVID-19 pandemic is recently considered as the most public health challenge with global dramatic changes on different aspects of life and health, including the psychological burden on individuals and communities. A convenience sample of youth (university students) aged 18-24 years was chosen in this crosssectional study that was conducted during the period from October through December 2020. The questionnaire included questions about COVID-19 and its effect on mental and social wellbeing.

Results: Out of the total 762 young adults who responded, $62 \%$ were females, with a mean age of $20.75 \pm 2.33$; $40.4 \%$ of them reported severely impaired social leisure activities; $14.7 \%$ expressed severely impaired private leisure activities; and $15.5 \%$ had severely impaired ability to form and maintain close relationships. Continuous feeling of nervousness, anxiety, stress, or exaggerated worries about the coronavirus was reported by $18 \%$, while $24.9 \%$ felt sad or depressed all the time, and $26.4 \%$ of the female respondents had depressive symptoms versus $22.5 \%$ males.
\end{abstract}

Conclusion: The findings of this study indicate that the COVID-19 pandemic had created severe limitations on people's social activities that may be associated with negative changes in mental condition.

Keywords: COVID-19, Perception, Social, Mental, Youth, Iraq

\section{Background}

In December 2019, a group of patients (in Wuhan, Hubei province, China) with pneumonia of unknown cause was confirmed to be infected with a novel coronavirus, known as 2019-nCoV that had not been previously detected in humans or animals. In March 2020,pandemic" [1-3]. This pandemic has been labeled as the most public health challenge in the last four decades because, in addition to the high rates of morbidity and mortality, it was associated with global dramatic changes in life including lifestyle, traveling, communications, and financial issues. All these changes created noticeable effects on different aspects of life and health, causing more psychological burdens on individuals and communities $[4,5]$.

In Iraq, which is known to have a vulnerable health system that was further weakened by years of war and

\footnotetext{
*Correspondence: ameelalshawi@gmail.com; ameel_med@uofallujah.edu.iq

${ }^{1}$ College of Medicine, University of Fallujah, Fallujah, Iraq

Full list of author information is available at the end of the article
}

sectarian conflicts, the first case reported was an international student in Najaf governorate on February 24, 2020, followed 3 days later by a second (national) case, which was followed by a series of cases in different provinces of the country. On March 17, 2020, the authorities imposed the lockdown, suspended schools, and closed mosques, malls, shops, casinos, and other crowded places. The fear of getting COVID-19 infection resulted in a strict limitation of movement and communication impairment in work that appeared to be associated with serious psychological distress such as anxiety and depression [6, 7]. Exposure (or fear of exposure) to the virus is an important risk factor of psychiatric symptoms as threat perception could be intensified for some people and reflect their fear of being exposed (or their relatives) to the virus $[8,9]$.

This study aims to help understand the social, behavioral, and psychological impacts of COVID-19 on Iraqi youth. 


\section{Methods}

\section{Study setting and study population}

This descriptive cross-sectional study (with an analytic element) was conducted during the period from October through December 2020, on a convenience sample of young adults aged 18-24 years that was collected from different Iraqi governorates. Data were collected online (a web-based survey), the questionnaire form was distributed electronically to the target population in different Iraqi governorates.

\section{Assessment tools}

The questionnaire consisted of a socio-demographic section that included age, gender, level of education, marital status, and residence. The second section (screening tool) included questions about COVID-19 and its possible effect on social life and behavior in order to assess the level of impairment the pandemic has caused. The questionnaire was borrowed from the "Australian National COVID-19 mental health, behavior and risk communication survey" [10] with some modifications to suit the Iraqi culture. These questions included ability to work, ability to study, home management (cleaning, tidying, shopping, cooking, looking after home or children, paying bills), and also social leisure activities (with other people), such as parties, bars, clubs, outings, visits, and home entertainment, in addition to private leisure activities (activities that are done alone) such as reading, gardening, sewing, and walking alone, on a scale ranging from "not at all impaired" to "very severely impaired" during the last 6 months.

The last group of questions was to illustrate the effect of COVID-19 on participants' mental health such as feeling nervous, anxious, stressed, or worried; having trouble sleeping or nightmares related to the coronavirus; and feeling sad or depressed during the last 6 months, with $5^{\circ}$ Likert scale (from not at all to all of the time) [11]. The questionnaire was translated from English to Arabic, then to English to enhance validity. Data were collected electronically using the survey monkey program.

\section{Ethical consideration}

At the top of the questionnaire form, a paragraph was added that refers to the consent of the participants to be involved in the survey after explaining to them its purpose and assuring the confidentiality of the information they give. The final ethical approval for the implementation of the study was obtained from the Scientific and Ethical Committee of the Medical College/University of Fallujah.

\section{Statistical analysis}

Data were presented as numbers and percentages. Chisquare test was used to assess the significance of association between variables with a cutoff point of $p$ value $\leq$ 0.05 to be considered as significant.

\section{Results}

A total of 762 youth was collected from different governorates, mainly Baghdad (50\%), 66.1\% of whom were females and $93.1 \%$ were single, and their mean age was $20.75 \pm 2.33$ - more details about the socio-demographic characteristics are shown in Table 1 which also demonstrates that $4 \%$ of the respondents were diagnosed as having coronavirus infection, $22.2 \%$ had a family member or know someone who had coronavirus, and $15.6 \%$ reported having a family member or knowing someone who died from coronavirus.

Table 2 shows that $40.4 \%$ of the respondents reported severely impaired social leisure activities (group activities), such as parties, celebrations, outings, visits, or home entertainment; $14.7 \%$ expressed severely impaired private leisure activities; and $15.5 \%$ of the participants had severely impaired ability to form and maintain close relationships during the period of the pandemic.

Table 3 clarifies that $18 \%$ of the respondents reported a continuous feeling of nervousness, anxiety, stress, or exaggerated worries about coronavirus, while $24.9 \%$ are feeling sad or depressed all the time; $35.8 \%$ of the participants had anxiety about COVID-19 in (most/all of the time); and $41.2 \%$ reported COVID-related depression in (most/all of the time).

The results also revealed that $26.4 \%$ of the female respondents had depression symptoms (all of the time) associated with COVID-19 versus $22.5 \%$ males with no significant gender difference (Table 3 ).

\section{Discussion}

Assessing the hazards of an infectious disease is usually a vital concern in epidemiology [12]. However, the rapid spread of an infectious disease is usually associated with anxiety, fear, psychological distress, and other mental symptoms [13].

The findings revealed a negative impact of COVID-19 on the social and mental wellbeing of youth. More than half of the respondents reported some impairment of social activities, and many of them reported "severely impaired" leisure activities; this could be attributed in part to the panic of being in contact with the "probably" infected persons in overcrowded places, and, on the other hand, to the lockdown that was imposed by the health and political authorities for more than 3 months. These findings are consistent with what was reported in some other studies $[5,14,15]$. 
Table 1 Socio-demographical characteristics of the sample

\begin{tabular}{|c|c|c|c|}
\hline & & No. & $\%$ \\
\hline \multirow[t]{3}{*}{ Gender } & Female & 473 & 62.1 \\
\hline & Male & 289 & 37.9 \\
\hline & & 762 & 100 \\
\hline \multirow[t]{2}{*}{ Marital status } & Single & 710 & 93.1 \\
\hline & Married & 52 & 6.8 \\
\hline Age $($ mean \pm SD) & $20.75+2.33$ & & \\
\hline I was diagnosed positive with coronavirus & & 31 & 4 \\
\hline I had symptoms but was never tested & & 24 & 3.1 \\
\hline Isolated or quarantined due to possible exposure & & 15 & 19.6 \\
\hline I have a family member or know someone who was diagnosed positive & & 169 & 22.2 \\
\hline I have a family member or know someone who died from coronavirus & & 119 & 15.6 \\
\hline
\end{tabular}

The incidence of mental symptoms is known to be lower in youth compared to other age categories. Meta-analysis of the prevalence of anxiety and depression among adolescents and young adults generated a pooled prevalence estimate of $19.1 \%$ and $14.3 \%$, respectively [16]; however, the current study showed a higher incidence of anxiety and depressive symptoms among youth-this could be attributed to the psychological consequences of the pandemic which created a feeling of panic from the sequels of COVID-19 especially after the accelerating registration of deaths.

Men are usually less vulnerable to suffer from mental symptoms than women $[17,18]$; however, the interesting finding in the current study was that the prevalence of mental symptoms in males is approximating that in females with no significant difference, this could be attributed to the effect of the prolonged lockdown and strict limitation of movement that was not experienced by males (especially youth-the most active age group) before the time of pandemic [19] although anxiety and nervousness were a bit more in women compared to men. The prolonged exposure of the Iraqis to continuous wars, sanctions, armed conflicts, and wide spectrum of violence for more than four decades [20, 21] might have a deep influence on their thoughts, feelings, and behaviors.

The feeling of anxiety (most/all of the time) was higher than what was reported among samples of university students in the United Arab Emirates, ${ }^{5}$ Australia, ${ }^{6}$ and in South-west Ethiopia [22]. This could be explained by differences in culture, instruments used, and sampling techniques.

The importance of this study comes from the validity of its genuine subject; however, the findings may be difficult to interpret because of the potential limitation of the sample size, due to the relatively low response rate attributed to the sensitivity of the subject and people avoidance to share information related to their psychological condition. Despite this limitation, these data allow important conclusions to be drawn about the social and mental burden of this newly emerging disease more broadly.

\section{Conclusions}

The findings of this study indicate that, so far, the COVID-19 pandemic had created severe limitations on social activities of the population that might be associated with negative changes in mental condition and

Table $\mathbf{2}$ Levels for social impairment caused by coronavirus pandemic

\begin{tabular}{|c|c|c|c|c|c|}
\hline & $\begin{array}{l}0 \\
\text { (Not at all) } \\
\text { No. (\%) }\end{array}$ & $\begin{array}{l}1 \\
\text { (little) } \\
\text { No. (\%) }\end{array}$ & $\begin{array}{l}2 \\
\text { (Somewhat) } \\
\text { No. (\%) }\end{array}$ & $\begin{array}{l}3 \\
\text { (Frequently) } \\
\text { No. (\%) }\end{array}$ & $\begin{array}{l}4 \\
\text { Severely impaired } \\
\text { No. (\%) }\end{array}$ \\
\hline Ability to work & $247(32.4)$ & $117(15.5)$ & $176(23.1)$ & $108(14.12)$ & $114(15)$ \\
\hline Ability to study & $193(25.3)$ & $122(16)$ & $156(20.5)$ & $137(18)$ & $154(20.2)$ \\
\hline Home management & $281(36.9)$ & $139(18.2)$ & $158(20.7)$ & $105(13.8)$ & 79 (10.4) \\
\hline Social leisure activities & $169(22.2)$ & $79(5.8)$ & $88(11.5)$ & $118(15.5)$ & $308(40.4)$ \\
\hline Private leisure activities & $311(40.8)$ & $145(19)$ & $124(16.3)$ & $70(9.2)$ & $112(14.7)$ \\
\hline Ability to form and maintain close relationships & $291(38.2)$ & $137(18)$ & $143(18.8)$ & $37(9.6)$ & $118(15.5)$ \\
\hline
\end{tabular}


Table 3 Statistics of mental health symptoms associated with COVID-19 pandemic

\begin{tabular}{|c|c|c|c|c|c|c|}
\hline & $\begin{array}{l}\text { Not at all impaired } \\
n(\%)\end{array}$ & $\begin{array}{l}\text { Little of time } \\
n(\%)\end{array}$ & $\begin{array}{l}\text { Some time } \\
n(\%)\end{array}$ & $\begin{array}{l}\text { Most of the time } \\
n(\%)\end{array}$ & $\begin{array}{l}\text { All the time } \\
n(\%)\end{array}$ & $P^{*}$ \\
\hline Feel nervous, anxious, stressed & $141(18.5)$ & $135(17.7)$ & $213(28)$ & $136(17.8)$ & $137(18)$ & \\
\hline Female & $86(18.2)$ & $82(17.3)$ & $127(26.8)$ & $83(17.5)$ & $95(20.1)$ & 0.42 \\
\hline Male & $55(19)$ & $53(18.3)$ & $86(29.8)$ & $53(18.3)$ & $42(14.2)$ & \\
\hline Have trouble sleeping or nightmares & $558(73.2)$ & $97(12.7)$ & $52(6.8)$ & $25(3.3)$ & $30(3.9)$ & \\
\hline Female & $347(73.4)$ & $58(12.3)$ & $33(7)$ & $17(3.6)$ & $18(3.8)$ & 0.95 \\
\hline Male & $211(73)$ & $39(13.5)$ & $19(6.6)$ & $8(2.8)$ & $12(4.2)$ & \\
\hline Feel sad or depressed & $164(21.5)$ & $146(19.2)$ & $138(18.1)$ & $124(16.3)$ & $190(24.9)$ & \\
\hline Female & $102(21.5)$ & $88(18.6)$ & $77(16.3)$ & $81(17.1)$ & $125(26.4)$ & 0.38 \\
\hline Male & $62(21.5)$ & $58(20.1)$ & $61(21.1)$ & $43(14.9)$ & $65(22.5)$ & \\
\hline
\end{tabular}

${ }^{*}$ Chi-square was used

could lead to a sort of social and psychological withdrawal, the duration and remote consequences of which are difficult to predict. Further national surveys with larger samples and in-depth analyses are required to more elaborate the effect of COVID-19 on the social and mental health of the Iraqi population.

\section{Abbreviation}

COVID-19: Coronavirus disease 2019

\section{Acknowledgements}

We are grateful to all the people who participated in the study.

\section{Authors' contributions}

Both authors contributed equally to the design, data collection, data analysis, and writing of the final article. The authors read and approved the final manuscript.

\section{Funding}

None.

\section{Availability of data and materials}

The datasets that were generated during and/or analyzed during the current study are available from the corresponding author on request.

\section{Declarations}

\section{Ethics approval and consent to participate}

Approved by the Ethical and Scientific Committee for research work in the Department of Family and Community Medicine, College of Medicine, University of Fallujah.

\section{Consent for publication}

Not applicable.

\section{Competing interests}

The authors declare that they have no competing interests.

\section{Author details}

${ }^{1}$ College of Medicine, University of Fallujah, Fallujah, Iraq. ${ }^{2}$ Global Health Department, University of Washington, Seattle, USA.
Received: 24 August 2021 Accepted: 25 September 2021

Published online: 12 October 2021

\section{References}

1. WHO. Novel coronavirus (2019-nCoV) situation report 2020. (Accessed 22 Dec 2020). https:/www.who.int/emergencies/diseases/novel-coronavirus-2 019?gclid=CjOKCQiAs5eCBhCBARIsAEhk4r7o2ohOVd4BuQdWnFN06TFPsjY8G.

2. Wu F, Zhao S, Yu B, Chen YM, Wang W, Song ZG, Hu Y, Tao ZW, Tian JH, Pei YY, Yuan ML, Zhang YL, Dai FH, Liu Y, Wang QM, Zheng JJ, Xu L, Holmes EC, Zhang YZ (2020) A new coronavirus associated with human respiratory disease in China. Nature 579(7798):265-269. https://doi.org/10.1038/s41586020-2008-3

3. Al-Hanawi MK, Angawi K, Alshareef $\mathrm{N}$ et al (2020) Knowledge, attitude and practice toward COVID-19 among the public in the Kingdom of Saud Arabia: a cross-sectional study. Front Public Health 8:217. https://doi.org/1 0.3389/fpubh.2020.00217

4. WHO. Impact of COVID-19 on people's livelihoods, their health and our food systems. (2020a). Available at: https://www.who.int/news/item/13-10-2 020-impact-of-covid-19-on-people\%27s-livelihoods-their-health-and-ourfood-systems.

5. Saravanan C, Mahmoud I, Elshami W, Taha MH (2020) Knowledge, anxiety, fear, and psychological distress about COVID-19 among university students in the United Arab Emirates. Front Psychiatry 11:582189. https://doi.org/1 0.3389/fpsyt.2020.582

6. Dawel A, Shou Y, Smithson M, Cherbuin N, Banfield M, Calear AL, Farrer LM Gray D, Gulliver A, Housen T, McCallum SM, Morse AR, Murray K, Newman E, Rodney Harris RM, Batterham PJ (2020) The effect of COVID-19 on mental health and wellbeing in a representative sample of Australian adults. Front Psychiatry 11:579985. https://doi.org/10.3389/fpsyt.2020.579985

7. James PB, Wardle J, Steel A, Adams J (2019) Post-Ebola psychosocial experiences and coping mechanisms among Ebola survivors: a systematic review. Trop Med Int Health 24(6):671-691. https://doi.org/10.1111/tmi.13226

8. Florin M, Pinar U, Chavigny E, Bouaboula M, Jarboui L, Coulibaly A, Lemogne C, Fournier L (2020) Socio-economic and psychological impact of the COVID-19 outbreak on private practice and public hospital radiologists. Eur J Radiol 132:109285. https://doi.org/10.1016/j.ejrad.2020.109285

9. Li Q, Guan X, Wu P, Wang X, Zhou L, Tong Y, Ren R, Leung KSM, Lau EHY, Wong JY, Xing X, Xiang N, Wu Y, Li C, Chen Q, Li D, Liu T, Zhao J, Liu M, Tu W, Chen C, Jin L, Yang R, Wang Q, Zhou S, Wang R, Liu H, Luo Y, Liu Y, Shao G, Li H, Tao Z, Yang Y, Deng Z, Liu B, Ma Z, Zhang Y, Shi G, Lam TTY, Wu JT, Gao GF, Cowling BJ, Yang B, Leung GM, Feng Z (2020) Early transmission dynamics in Wuhan, China, of novel coronavirus-infected pneumonia. N Engl J Med 382(13):1199-1207. https://doi.org/10.1056/ NEJMoa2001316

10. Dawel A (2020) Australian National COVID-19 mental health. In: Behavior and risk communication survey. Australia: Australian National University, School of Psychology, Australia (not published) Protocol number: 2020/152

11. Mundt J, Marks I, Shear K et al (2020) The Work and Social Adjustment Scale: a simple measure of impairment in functioning. Brit J Psychiatry 180(5):461-464. https://doi.org/10.1192/bjp.180.5.461 
12. Verity R, Okell LC, Dorigatti I et al (2019) Estimates of the severity of coronavirus disease a model-based analysis. Lancet Infect Dis 20:669-677 2020 Mar 30

13. Cheng SKW, Wong CW, Tsang J et al (2004) Psychological distress and negative appraisals in survivors of severe acute respiratory syndrome (SARS). Psychol Med 34(7):1187-1195. https://doi.org/10.1017/S0033291704002272

14. Alyami M, Albuquerque V, Krageloh C et al (2021) Effects of fear of COVID19 on mental well-being and quality of life among Saudi Adults: a path analysis. Saudi J Med Sci 26(1):24-30. https://doi.org/10.4103/sjmms.sjmms_ 630_20

15. Dubey S, Biswas P, Ghosh R et al (2020) Psychosocial impact of COVID-19, diabetes \& metabolic syndrome. Clin Res Rev 14(5):779-788. https://doi. org/10.1016/j.dsx.2020.05.035

16. Barker M, Beresford B, Bland M et al (2019) Prevalence and Incidence of anxiety and depression among children, adolescent, and young adults with life-limiting conditions: a systematic review and meta-analysis. JAMA Pediatr 173(9):835-844. https://doi.org/10.1001/jamapediatrics.2019.1712

17. Younis M, Lafta R (2021) Iraqi women's plight: odds, violence, and mental illnesses, review article. Int J Soc Psychiatry 67(2):002076402110036. https:// doi.org/10.1177/00207640211003602

18. Lafta R, Dhiaa S, Tawfeeq W et al (2016) Association of violence with anxiety and depression among Iraqi junior doctors. Int J Appl Psychol 6(6):163-170. https://doi.org/10.5923/j.ijap.20160606.01

19. Verma S, Mishra A (2020) Depression, anxiety, and stress and sociodemographic correlates among general Indian public during COVID-19. Int J Soc Psychiatry 66(8):756-762. https://doi.org/10.1177/0020764020934508

20. Al Shawi A, Tawfeeq W, Dhiaa S et al (2017) The impact of violence on Iraqi junior doctors. MOJ Public Health 5(1). https://doi.org/10.15406/mojph.2017. 05.00115

21. Lafta R, Al-Nuaimi M (2019) War or health, a four decade armed conflict in Iraq. Med Conf Surv 35(3):209-226. https://doi.org/10.1080/13623699.2019.1 670431

22. Aylie NS, Mekonen MA, Mekuria RM (2020) The psychological impacts of COVID-19 pandemic among university students in Bench-Sheko Zone, South-west Ethiopia: a community-based cross-sectional study. Psychol Res Behav Manag 13:813-821. https://doi.org/10.2147/PRBM.S275593

\section{Publisher's Note}

Springer Nature remains neutral with regard to jurisdictional claims in published maps and institutional affiliations.

\section{Submit your manuscript to a SpringerOpen ${ }^{\circ}$ journal and benefit from:}

- Convenient online submission

- Rigorous peer review

- Open access: articles freely available online

- High visibility within the field

- Retaining the copyright to your article

Submit your next manuscript at $\boldsymbol{\nabla}$ springeropen.com 